\title{
Student response systems and learner engagement in large classes
}

Active Learning in Higher Education 20I4, Vol. I5(I) II -24

(C) The Author(s) 2013

Reprints and permissions: sagepub.co.uk/journalsPermissions.nav DOI: I0.II77/|4697874|35|4648 alh.sagepub.com

\author{
Graham Heaslip \\ NUI Maynooth, Ireland
}

\section{Paul Donovan}

NUI Maynooth, Ireland

\section{John G Cullen}

NUI Maynooth, Ireland

\begin{abstract}
The use of student response systems is becoming more prevalent in higher level education. Evidence on the effectiveness of this technology can be an important resource for tutors seeking to engage with learners and raise the quality of learning experiences. Student response systems have been found to increase student engagement and participation in the classroom, yet few studies examine why this is so. This research seeks to explore the effects of student response systems on student participation in large classes. The methods used included both quantitative and qualitative data. A pre-test/mid-test/post-test design (quantitative approach) was deployed to examine the effects of a classroom response system on interactivity. Students involved in a final year undergraduate business course took part in investigating the use of student response systems from the student perspective. Qualitative data were collected to identify the strengths and weaknesses of using a classroom response system to enhance classroom interaction through semi-structured interviews. This research builds on previous studies by investigating why students become more participatory, interactive and engaged during learning sessions which utilise student response systems. Implications for teaching practice are discussed, and avenues for future research on student response systems and student engagement in large class scenarios are outlined.
\end{abstract}

\section{Keywords}

Classroom interactivity, clickers, student engagement, student response system

\section{Corresponding author:}

Graham Heaslip, Department of Management, School of Business, North Campus, NUI Maynooth, Maynooth, Co.

Kildare, Ireland.

Email: graham.heaslip@nuim.ie 


\section{Learner engagement}

Despite the enormous amount of published research on encouraging student responsiveness and engagement in higher education, some have noted that in-class passivity among students in higher education is a growing problem (Cutler, 2007). Where it occurs, such lack of engagement can create difficulties for the effective conduct of learning events. Large class sizes have become a feature of modern higher level institutions due to staffing and funding issues (Cullen, 2011). Wentling et al. (2007) posit that it is vital learners remain involved in order to achieve their potential academically. Although university programmes have traditionally involved large groups of undergraduate students, particularly at earlier stages of higher education, some have expressed that this form of 'massification' has spread throughout higher level education which could possibly increase the risk of learner disengagement (Flynn, 2010; Usher and Cervenan, 2005). At the same time, there has been a corresponding growth in the literature on student involvement, engagement and participation in higher level education, but an unintended side effect of this has been that these terms are often used interchangeably, which can result in confusion about what is meant in relation to them. Clarification is required to allow for greater precision and accuracy in their use. Within this broad area of study on involvement, engagement and participation, some have concentrated on the active involvement of the learner in the classroom situation (Siau et al., 2006). Keough (2012) has indicated that a significant lacuna exists in relation to research on student response systems (SRSs) in the field of education. Within the classroom setting, some have focused on the use of technology, particularly SRSs, as a means of promoting involvement (Kay and LeSage, 2009). Although these approaches are welcome, little research has examined how this technology actually affects student behaviour (Roschelle et al., 2004). The next section reviews this literature and examines overlaps between the concepts of involvement, engagement and participation, with a view to clarifying what is meant by each. In reviewing the research on SRS, specific attention is given to learner involvement.

\section{Involvement, engagement, participation and SRSs}

Studies on involvement emphasise time and energy devoted to task (CIRP and HERI, 2008) and examine how the learner is involved both academically and socially. The concept of involvement was first introduced by Astin (1975) as part of extensive research on the retention of students. He subsequently developed the concept to describe it as the physical and psychological energy that the learner gives to the learning experience (Astin, 1984). Astin used the term 'vigilance' to describe maintenance of attention to the task of learning. He concluded that vigilance and the time given to the task were too narrow to account for his understanding of involvement. Involvement is a wider construct including a greater range of experience and behaviours and includes elements of the environment. In general, the concept of involvement has led to studies of class settings and contexts in the wider environment. The unit of focus is on the individual and the behaviour of that individual in becoming and staying involved in their education. Institutions have responded and have implemented practices implied by the research (CIRP and HERI, 2008). Involvement has accordingly been linked to a wide range of positive outcomes for students (Wolf-Wendel et al., 2009).

Engagement refers to the time and effort that learners invest in studies and other activities that lead to student success (Kuh, 2001). One initiative that has led to significant work in promoting the concept of engagement is the National Survey of Student Engagement (NSSE, 2002). The NSSE assesses how engaged learners are in research-established good practices in education and assesses what they derive from their higher education experience (Wolf-Wendel et al., 2009). The 
instrument surveys behaviours of students which are desirable for positive learning and personal college outcomes (NSSE, 2002). In this survey, students report on their usage of time, answer questions on the quality of college life and express how they feel that they have developed personally as a result of their college engagement. The survey reports on key benchmarks of institutional effectiveness such as academic challenge, active and collaborative learning, student-faculty interaction, enriching educational experiences and supportive campus environment (Wolf-Wendel et al., 2009).

In these areas, the concept of engagement becomes distinct from that of involvement in that it refers to both student and institutional activities that lead to desired outcomes of all stakeholders, whereas involvement refers to student activities only. Engagement encourages reflection and action by the higher education institution in relation to best practice (Wolf-Wendel et al., 2009). Indeed Zepke and Leach's (2010) synthesis of the research literature on student engagement in higher education demonstrated that student engagement has been studied from a range of varying perspectives, but share a focus on relating the 'institutional' or external aspects of engagement to intrinsic motivation to learn among students.

The meaning of participation may vary depending on the context in which it is used. Some tutors use participation as a means of assessing student performance. In the literature, participation is often discussed in relation to five distinct elements: preparation, contribution to discussion, group skills, communication skills and attendance (Dancer and Kamvounias, 2005). A criticism of participation as a construct is that it is measured principally in quantitative ways (Rocca, 2010). This suggests that research has measured the easily measurable. A qualitative approach may be required to find explicit meaning among learner responses. There are also differences in perceptions between students and tutors. Students are found to have a wider appreciation of involvement, whereas tutors perceive it as being in-class discussion (Bippus and Young, 2000). There are various ways of assessing participation, including using self-report, peer evaluation and estimates of other tutors and researchers. The stance of the rater needs to be taken into account as bias and differences in perceptions abound. Constantly using the same operational definition of in-class student participation may help prevent bias. One definition comprises 'asking questions, raising one's hand and making comments' (Rocca, 2010: 188). Siau et al. (2006) have developed an overlapping concept describing participation in the classroom. This is called interactivity. Accordingly, their definition describes interactivity as the 'active involvement and participation of students in the classroom' (Siau et al., 2006: 400).

Much of the literature has welcomed the use of SRS in promoting learner involvement (Bergtrom, 2006; Caldwell, 2007; Draper and Brown, 2004; Latessa and Mouw, 2005; Preszler et al., 2007; Simpson and Oliver, 2007). Many benefits have been ascribed to the use of SRS in the classroom including attendance, performance and involvement of students (Salemi, 2009). Research suggests that learners favour SRS and believe that its use in the classroom is advantageous to learning (Judson and Sawada, 2002). Others are more cautious suggesting that there is little that is known of how these technologies actually work in practice and what social infrastructure is needed to support them (Roschelle et al., 2004). One of the most nuanced findings emanating from research on how students use SRS was from Graham et al.'s (2007) claim that learners were more positive about SRS which were used in a formative fashion, rather than solely being compelled to use it for grading or attendance. In particular, it was most positively received among students who, for whatever reasons, were usually more reluctant to participate in class.

Student preferences for SRS have been established in the literature (Beekes, 2006; Elliott, 2003), but what is less well understood is why learners become more interactive while using SRS (Kay and LeSage, 2009). Student preferences for using SRS may be based on many factors 
including the engagement of committing to an answer, higher attention levels due to breaks from lectures and immediate formative assessment and increased discussion (Preszler et al., 2007). Learners may be enamoured of technology and may enjoy using the handsets. They may also experience fun while making frequent asides and jibes to fellow students as the results are being prepared and displayed by SRS. There may also be excitement associated with this technology because of its use on TV game shows such as 'Millionaire' (Beekes, 2006).

Learners and tutors agree that participation in the classroom is a benign concept despite the absence of research into why and how students become engaged. There has been little research into the underlying mechanisms which are at play in this construct. It is usually assumed that learners are engaged simply by being involved in the learning process (Kay and LeSage, 2009). Technology, in the form of SRS, has been proposed as a means of increasing student participation. Little is known, however, of how and why students become more participatory when using SRS (Roschelle et al., 2004). The effect of learning style also on student behaviour cannot be ignored. Some learners may be more effective in learning while remaining quiet and attentive. Attempts to engage them in activities which only serve to suit a tutor concept of participation may lead to ineffective teaching. If we understand more clearly how SRS affects student motivation to become involved in class, it will be easier to evaluate more effectively technological solutions such as SRS. To this end, the following questions are asked:

Why are students more participatory when using SRS?

What factors do learners perceive encourage their participation in the classroom when using clickers?

How does SRS influence the motivation of students to become more engaged in classes?

\section{Research methodology}

Action research was used, comprising two cycles.

\section{Participants}

During semester 2 (January to May) in 2011, the School of Business at a small Irish university implemented a trial of SRSs to second-year students taking the Operations and Supply Chain Management module. The total student participation for the study was $120(\mathrm{n}=120)$. The Operations and Supply Chain Management course was offered in a small public university to undergraduate students in several areas, including Accounting, Management, Entrepreneurship, Equine Business and Arts. The Operations and Supply Chain Management module is a 16-week semester course that introduces students to the concepts, processes and modelling techniques used. The course was conducted in a traditional lecture theatre and was mainly lecture based. Before implementing a classroom response system in the classroom, oral questioning and answering was the main mechanism for facilitating instructor-student interaction.

\section{Technology used}

The SRS technology chosen for use in this study was the $\mathrm{i}>$ clicker classroom response system by i>clicker. This system included individual handheld, radio frequency (RF) wireless handsets for student and instructor use, and a receiver that was plugged into the existing lecture theatre computers to receive and compute data. There was no need to download additional software from the i>clicker website. To operationalise, questions were written directly onto lecture slides in 
PowerPoint by the instructor. The audio visual equipment in the lecture theatre was used to project the PowerPoint slides for viewing by the class. The $\mathrm{i}>$ clicker RF wireless handsets were purchased by the department and made available to students at no cost. The $\mathrm{i}>$ clicker technology provided the following features:

Simplicity: Multiple choice, True/False and Yes/No entry capability.

Reliability: The $\mathrm{i}>$ clicker organisation provided technical support if needed.

Accessibility: The design of six large buttons with raised letters along with light-emitting diode (LED) lights for notification makes the remote easy to navigate.

\section{Data collection}

A number of criteria have been investigated regarding clicker use, and the methods used to obtain outcome data differ between studies. Some studies employ student surveys with Likert-type scale questions and open-ended questions, whereas others rely on objective measures such as actual grades and instructor-maintained attendance records. Many ad hoc inventories and questionnaires exist in the literature, but few instruments are fully validated. One such validated instrument, developed to assess not only individual participation but also class participation (Siau et al., 2006), was used to collect quantitative data and an original questionnaire was developed by the researchers in order to collect qualitative data. To control for the effect of the teaching method, a similar teaching sequence was utilised in all sessions during the semester.

To assess the effect of the classroom response system on interactivity in the classroom, a pretest/mid-test/post-test design was adopted. The assessment consisted of five parts. A total of 120 students agreed to take part in the pre-test, mid-test and post-test surveys. Students were also offered the opportunity to provide qualitative comments regarding the use of SRS in the class.

\section{Pre-test}

Before implementing the SRS in the classroom, each student was given a pre-test questionnaire (see 'Survey: pre-test questionnaire') to evaluate their level of interactivity in the classroom and the overall interactivity of the class. The pre-test was conducted at the beginning of the semester in January 2011 before the SRS was introduced.

\section{Survey: pre-test questionnaire}

Complete the form as follows:

1. You are given statements in which you have to indicate your preferred response.

2. The responses you can indicate vary from 1, indicating that you strongly disagree with the statement, to 5, indicating that you strongly agree with the statement. 
3. Insert a tick to indicate your preferred response to the statement posed.

4. All statements to be answered.

Individual degree of interactivity (your interactivity) (I: strongly disagree, 5: strongly agree)

\begin{tabular}{|c|c|c|c|c|c|c|}
\hline \multirow[t]{2}{*}{ Number } & \multirow[t]{2}{*}{ Statement } & \multicolumn{5}{|c|}{ Opinion } \\
\hline & & I & 2 & 3 & 4 & 5 \\
\hline I & I interact with the lecturer in class. & & & & & \\
\hline 2 & I am involved in learning during class. & & & & & \\
\hline 3 & I am engaged in class. & & & & & \\
\hline 4 & I am attentive in class. & & & & & \\
\hline 5 & I participate in class discussion. & & & & & \\
\hline 6 & I provide my opinion to questions from the instructor during the class. & & & & & \\
\hline 7 & I receive feedback in class on my understanding of the course materials. & & & & & \\
\hline 8 & I receive feedback from the lecturer during the class. & & & & & \\
\hline 9 & I can gauge whether I am following the course materials during the class. & & & & & \\
\hline 10 & $\begin{array}{l}\text { I can assess my understanding of the course materials with respect to } \\
\text { other students during the class. }\end{array}$ & & & & & \\
\hline
\end{tabular}

Overall degree of interactivity (classes interactivity) (I: strongly disagree, 5: strongly agree)

\begin{tabular}{|c|c|c|c|c|c|c|}
\hline \multirow[t]{2}{*}{ Number } & \multirow[t]{2}{*}{ Statement } & \multicolumn{5}{|c|}{ Opinion } \\
\hline & & I & 2 & 3 & 4 & 5 \\
\hline I & Students interact with the lecturer in class. & & & & & \\
\hline 2 & Students are involved in learning during class. & & & & & \\
\hline 3 & Students are engaged in class. & & & & & \\
\hline 4 & Students are attentive in class. & & & & & \\
\hline 5 & Students participate in class discussion. & & & & & \\
\hline 6 & $\begin{array}{l}\text { Students provide their opinions to questions from the } \\
\text { instructor during the class. }\end{array}$ & & & & & \\
\hline 7 & $\begin{array}{l}\text { Students receive feedback in class on their understanding of } \\
\text { the course materials. }\end{array}$ & & & & & \\
\hline 8 & Students receive feedback from the lecturer during the class. & & & & & \\
\hline 9 & $\begin{array}{l}\text { Students can gauge whether they are following the course } \\
\text { materials during the class. }\end{array}$ & & & & & \\
\hline 10 & $\begin{array}{l}\text { Students can assess their understanding of the course } \\
\text { materials with respect to other students during the class. }\end{array}$ & & & & & \\
\hline
\end{tabular}

\section{Implementation of the classroom response system in the classroom}

After the pre-test, the SRS was introduced in the class. Thus, the first research cycle (first half of the semester, February to March 2011) was conducted utilising the SRS and the second research cycle (second half of the semester, March 2011 to May 2012) utilised the response system with modifications from feedback, examination of data collected and reflection by the tutor. 


\section{Mid-test}

The mid-test questionnaire (which was the same questionnaire as that issued for the pre-test) was applied at set intervals during the semester. Applying the questionnaire over several weeks allowed for problems such as unfamiliarity with the teaching or the technology to be controlled.

\section{Post-test}

After implementing the SRS in the class for 12 weeks (that is, during the first and second half of the semester), a post-test questionnaire (see 'Survey: post-test questionnaire') was given to the students to capture their individual interactivity and the overall interactivity in the classroom.

Survey: post-test questionnaire.

Perceived ease of use of clickers (I: strongly disagree, 5: strongly agree)

\begin{tabular}{|c|c|c|c|c|c|c|}
\hline \multirow[t]{2}{*}{ Number } & \multirow[t]{2}{*}{ Statement } & \multicolumn{5}{|c|}{ Opinion } \\
\hline & & I & 2 & 3 & 4 & 5 \\
\hline I & It is easy for me to become skilful at using the clickers. & & & & & \\
\hline 2 & I find it easy to get the clickers to work as intended. & & & & & \\
\hline 3 & I find the clickers easy to use. & & & & & \\
\hline
\end{tabular}

Perceived usefulness of clickers (I: strongly disagree, 5: strongly agree)

\begin{tabular}{lllll}
\hline Number & Statement & Opinion & \\
\cline { 3 - 4 } & & 2 & 3 & 4 \\
\hline 1 & Using the clickers increases my interaction in the class \\
2 & Using the clickers makes it easier for me to interact in the class & & \\
3 & I find the clickers useful in enhancing my interaction in the class & & \\
\hline
\end{tabular}

What are the advantages and disadvantages of using the clickers in the lecture?

Again, this questionnaire was the same as the pre-test and mid-test, although the following was added to the post-test one. Perceived usefulness and perceived ease of use of the technology were also captured in the questionnaire. Perceived usefulness is defined as the extent to which a person believes that using a particular technology will enhance his or her performance, and therefore, is an indicator of an individual's extrinsic motivation to use a technology. Perceived ease of use refers to the degree to which a person believes that the use of a particular technology will be free of effort and is, therefore, an indicator of an individual's intrinsic motivation to use a technology. Perceived ease of use and perceived usefulness were adopted from the Technology Acceptance Model (TAM) and are used to predict users' intention to use new information technology (Davis, 1989; Davis et al., 1989).

\section{Qualitative data collection}

Qualitative data were collected at the end of week 6 (end of research cycle 1) and at the end of week 11 (end of research cycle 2). The qualitative data were collected using two methods, namely, a one-to-one semi-structured interview and student evaluations (see 'Student evaluations'). 
The interviews were conducted with a selection of learners comprising $25 \%$ of the total group (30 students). The interview also used the critical incident method of inquiry (Flanagan, 1954). This method assisted in gaining insight into learner experiences in the SRS condition to establish and explore any perceived relationship between the use of SRS and student participation. A sample question from this interview is 'at what point during the sessions did you feel most participatory?' Subsequent follow-up questions could elicit why this was so and what was happening at the time.

Student evaluations.

Student name [optional] Session:

Please circle your appropriate rating below.

Have you enjoyed using clickers in lectures?

\section{$(:):$}

Have you found the clickers easy to use?

\section{$\otimes(:)$}

Have you felt more involved in this module by using clickers?

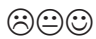

Are you engaged more with the content of this module by using clickers?

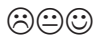

Do you participate in class discussion?

\section{$\therefore:(:)$}

Overall, please rate YOUR experience of this module.

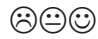

If so, please indicate which approaches you are interested in receiving more feedback on here.

\section{Instrument development and validation}

Although interactivity is considered important in teaching and learning, no instrument for measuring interactivity has been developed. Most of the studies are either conceptual in nature (BannanRitland, 2002; Chou, 2003; Roblyer and Wiencke, 2003; Sims, 2003) or merely reporting applications (Davis, 2003; Stuart et al., 2004). Thus, an instrument for measuring classroom interactivity was developed and validated. To examine the effect of the classroom response system on interactivity in the classroom accurately and systematically, conceptual definitions from prior literatures were reviewed to develop the instruments. Ten items were developed to measure the construct of interactivity. 
The constructivist model of learning suggests that learners' engagement and attention are important in learning. Therefore, interactivity can be measured through students' involvement in the class (items 1 and 2), students' engagement in the class (items 3 and 4), students' participation in the class (items 5 and 6), students receiving feedback from instructors (items 7 and 8) and students' self-assessment (items 9 and 10). See mid-test, post-test questionnaire and student evaluations for the items.

Each question is measured using a 5-point Likert scale with 1 representing 'strongly disagree' and 5 representing 'strongly agree'.

\section{Results}

\section{Action research cycle I}

Comments that students made on the post-test questionnaire, student evaluation forms and in interviews were those such as 'The clickers are great fun to use', 'I am learning so much more through using clickers', 'Helps to get better understanding of material' and 'Gets class involved'. Not surprising, in the interviews and on the comments left on the post-test questionnaire, interactivity was one of the most highly cited benefits of the SRS. Students highlighted that the use of the SRS increased their involvement in the class, helped promote more class participation, allowed them to get immediate feedback and enabled them to assess their understanding relative to those of the other students.

A surprising finding was how important anonymity was to students. As the class was an undergraduate cohort, it is assumed that students are comfortable with their peers. However, comments from students in interviews and the post-test questionnaire highlight the benefits of anonymity with one student explaining 'anonymity is great, no fear of humiliation if I get a question wrong'. SRS allows every student the chance to answer every question without being embarrassed if their answer is wrong. The anonymity feature of the SRS increases students' willingness to participate in the class. Further comments from the post-test questionnaire note the student's feelings: 'Anonymity helps me - don't feel humiliated if I get the question wrong ... more interactive and participative in lectures'. With the SRS, every student has the chance to answer every question without being embarrassed if their answer is wrong. The anonymity feature of the SRS appeared to increase student's willingness to participate in the lecture. A regular comment from the post-test questionnaire would be 'they make the class more interactive and interesting'. In addition, another relates,

There is no humiliation in getting a question wrong. Because of the anonymity and the fact that no one is sure of the answer students are trying harder to get questions right as there are no consequences for selecting a wrong answer. For a technology savvy generation (mobile phones, Twitter, Facebook, emails, etcetera) it is surprising how we value our anonymity.

In a focus group discussion with students, one student remarked that students 'would like to see their clicker results compared to other students'. Other members of the focus group further noted that students were very keen on seeing their results compared to other students. This proved puzzling as earlier in the process students were highlighting the benefits of anonymity. To overcome this dilemma, we adopted a suggestion by the focus group that in the second half of the semester we should use clickers in lectures in groups rather than as individuals. Each week results were produced comparing all the groups, thus encouraging the competitive spirit that was forming in the class. 


\section{Action research cycle 2}

Cycle 2 was from weeks 8 to 13. During this period, students preselected themselves into groups. For each lecture, the students sat in their groups (each group comprising five students - which the students preselected) and answered the clicker questions in groups. For the second research cycle, only one SRS was distributed to each group. This handset was registered to facilitate the capturing and recording of data for each group.

At the beginning of each lecture, a slide indicating how every group had fared answering the previous week's questions was provided. This slide was eagerly awaited each week and provided an opportunity for some banter before beginning the lecture. Comments from students in week 11 indicate that they were enjoying the use of clickers and the competitive nature between groups. Two comments that highlight the students' views were 'Our group needs to pull up its socks ... we are in the middle' and 'Loving the competition between groups ... keeps us on our toes'.

After one lecture in cycle 2, we spoke to 10 students who indicated that the discussions in the group were extremely beneficial and assisted in learning more about the module.

\section{Statistical analysis}

The descriptive statistics indicate that the interactivity at both the individual and class levels increased after using the SRS in the classroom. Before the implementation of the classroom response system, the average level of interactivity at the individual level was 3.1 and that for the overall class interactivity was 3.3. After using the classroom response system, the average level of interactivity at the individual level was increased to 4.1 and that of the overall class interactivity was increased to 4.4 .

A paired sample t-test was run to test for statistical significance. For interactivity at the individual level, the statistics show that interactivity has been increased significantly $(\mathrm{t}=4.057, p=$ $0.002)$. For overall class interactivity, the increase is also statistically significant $(\mathrm{t}=4.378, p=$ 0.000). The results of the t-tests suggest that SRSs significantly increase interactivity at both the individual and class levels.

The reliability of the interactivity instruments was also assessed in the pre-test and post-test. In the pre-test, the Cronbach's alpha coefficient for individual interactivity is 0.82 and that for class interactivity is 0.89 . In the post-test, the Cronbach's alpha coefficient for individual interactivity is 0.91 and that for class interactivity is 0.94 . The very high Cronbach's alpha coefficients indicate that the instruments are highly reliable.

The mean for perceived usefulness is 4.1 (out of 5), and the mean for perceived ease of use is 4.3 (out of 5). The relatively high means suggest that the students perceived the use of the SRS to be free of effort, and they believed that using the classroom response system made it easier for them to interact in the classroom. The reliability tests show that the Cronbach's alpha coefficient for perceived usefulness is 0.96 and that for perceived ease of use is 0.73 . Both are above the 0.70 threshold (Nunnally, 1978).

\section{Discussion and conclusion}

Involvement, participation and engagement are issues of critical importance to institutes of higher education today. SRSs are widely promoted as a means by which students may become more engaged in class. Research had not studied extensively the student perspective on the factors that encourage participation when using clickers (Roschelle et al., 2004). The study described here found that students became more engaged when clickers were in use in the lecture room than when 
they were not. The findings of this study also suggest that students appreciate the anonymity afforded by clickers when responding to the lecturer's questions in class. Students rated highly the ease of use of the clickers, also suggesting that earlier reports in the research regarding technical difficulties (Graham et al., 2007) may have been resolved.

Students in this study appreciated the 'fun' element in the use of clickers in the classroom. Although enjoyment and learning are by no means mutually exclusive, clearly educators must satisfy themselves that the enjoyment is also coexistent with student learning when using SRS. Earlier work suggests mixed results when researching the direct educational outcomes of students' use of clickers in the classroom (Judson and Sawada, 2002). Although indirect measures such as enjoyment, involvement, participation and fun are all positive, further research is required to seek more tangible measures of the effectiveness of SRS perhaps even as a means of informing students regarding the effectiveness of using clickers.

The students' appreciation of the value of anonymity while using clickers was at once understandable and also somewhat disappointing. Students in large classes may be forgiven for remaining passive in open session, saving their engagement for when it is possible to do so anonymously with clickers. However, when one considers that in every other sphere of their use of technology in their daily lives, for example, smart phones, Facebook and Twitter, their personal identity is proudly broadcast to the world. Clearly, they are much more comfortable sharing personal opinions and details with friends and strangers alike in social media circumstances than they are with sharing their opinions on learning subjects in classrooms. Obviously, with social media, the environment provides a sense of distance and protection from the audience not available in the classroom. However, this behaviour in class does point to a certain immaturity in classroom relationships and processes and should be studied further.

Despite the affection for anonymity as individuals, the students in this study craved direct feedback on their performance in the group settings. Furthermore, the element of competition between groups emerged and, rather than being seen as threatening to them, was welcomed wholeheartedly. Students viewed this element as being an essential stimulus to learning. Once the threat to the individual was no longer present, the students could readily accept feedback on group performance and willingly compared intergroup scores seeing this as a motivating factor. There are opportunities here for further research into the reasons why students are more reticent in engaging in the learning environment than they are in the social media sphere.

This research aimed to address some of the gaps on research on SRSs and learner engagement. First, it has attempted to address the longstanding lacuna on SRS in the classroom identified by Keough (2012). Second, it has done so from the perspective of the student, rather than that of the tutor (Kay and LeSage, 2009). The research question asked whether SRS enhanced student participation in classrooms and the data support an affirmative response to this question. A mobile SRS has the potential to enhance and improve learning. The findings from this study indicate that the SRS can effectively enhance interactivity in the classroom. Incorporating the SRS in the classroom enables students to participate more in the classroom, provide opinions to questions from the instructor, receive feedback from the instructor during the class regarding their understanding of the course materials, gauge whether they are following the course materials and assess their understanding of the course materials with respect to the other students in the class. In other words, students are more engaged, more attentive and more involved in the class. Students perceived the SRS (clickers) to be easy to use and useful for their learning.

There are, naturally enough, limitations to any study. One limitation here is the size of the classes in the sample. The sample size in this study was 120 students. There is a requirement to repeat this research in larger groups. A second limitation of the study is the novelty value of SRS with learners. Accordingly, there is the possibility of fatigue. Future work should explore attitudes 
of students who have used SRS over a longer period of time (over, say, 2 or 3 years of an undergraduate programme) to see whether these have changed over time. A third limitation is that only one module was selected for the study. This involved one lecturer conducting the teaching, the use of the clickers, the interviews and the surveys. It is plausible that students' responses to the research were influenced by their relationship with the lecturer. There should be further research with separate source and delivery of the teaching and the research activities. In addition, there should be further research with multiple modules with care taken not to confound the results with markedly different teaching pedagogies or styles. A fourth limitation is the timing of the research. By the time the research was conducted, the use of clickers was firmly established in the School. In fact, their purchase and use by students was compulsory. Given this committed stance by the School, it is possible that students were influenced in their attitudes to the SRS. In addition, the individual lecturer's own stance and position on SRS is likely to have been known to students at the time of participating in the research. This knowledge may have influenced the results.

This study supports earlier research in suggesting that clickers can play a key role in delivering pedagogical outcomes, such as classroom engagement, involvement, participation and enjoyment. Students in the study appreciated also the anonymity afforded to them by SRS, yet at the same time welcomed the feedback that competition delivered to groups of which they were members. While clickers may be useful, some degree of caution is required, for as instructors, our primary concern is to enhance the student's development through effective learning. It is possible that positive experiences with SRS leading to greater involvement, participation and engagement may also lead to better learning outcomes for students, but this has not been firmly established by research. Lecturers could do worse than to continue the work of this study and to dedicate time in class to discuss if and why clickers are beneficial to students. In becoming more reflexive about their pedagogy, students and teachers may learn much more about how SRS and other technologies influence learning in the classroom.

\section{Funding}

This research received no specific grant from any funding agency in the public, commercial, or not-for-profit sectors.

\section{References}

Astin AW (1975) Preventing Students from Dropping Out. San Francisco, CA: Jossey-Bass.

Astin AW (1984) Student involvement: A developmental theory for higher education. Journal of College Student Personnel 25(4): 297-307.

Bannan-Ritland B (2002) Computer-mediated communication, eLearning, and interactivity: A review of the research. Quarterly Review of Distance Education 3(2): 161-79.

Beekes W (2006) The 'Millionaire' method for encouraging participation. Active Learning in Higher Education 7(1): 25-36.

Bergtrom G (2006) Clicker sets as learning objects. Interdisciplinary Journal of Knowledge and Learning 2. Available at: http://www.ijello.org/Volume2/v2p105-110Bergtrom.pdf (2010, accessed 9 May 2010).

Bippus AM and Young SL (2000) What behaviours reflect involvement in a course? Students' perceptions and differences between high and low communication apprehensive. Communication Research Reports 17(2): 310-9.

Caldwell JE (2007) Clickers in the large classroom: Current research and best-practice tips. CBE-Life Sciences Education 6(1): 9-20.

Chou C (2003) Interactivity and interactive functions in web-based learning systems: A technical framework for designers. British Journal of Education Technology 34(3): 265-79.

CIRP and HERI (2008) The Cooperative Institutional Research Program Freshman Survey. Available at: http://www.heri.ucla.edu/PDFs/HERI-CIRP_Portfolio.pdf (2010, accessed 27 July 2010). 
Cullen JG (2011) The writing skills course as an introduction to critical practice for larger business undergraduate classes. International Journal of Management Education 9(4): 25-38.

Cutler A (2007) Creeping passivity. Journal of College Science Teaching 36: 6-7.

Dancer D and Kamvounias P (2005) Student involvement in assessment: A project designed to assess class participation fairly and reliably. Assessment \& Evaluation in Higher Education 30(4): 445-54.

Davis F (1989) Perceived usefulness, perceived ease of use and user acceptance of information technology. MIS Quarterly 13(3): 319-40.

Davis F, Bagozzi RP and Warshaw PR (1989) User acceptance of computer technology: A comparison of two theoretical models. Management Science 35(8): 982-1003.

Davis S (2003) Observations in classrooms using a network of handheld devices. Journal of Computer Assisted Learning 19(3): 298-330.

Draper SW and Brown MI (2004) Increasing interactivity in lectures using an electronic voting system. Journal of Computer Assisted Learning 20(2): 81-94.

Elliott C (2003) Using a personal response system in economics teaching. International Review of Economics Education 1(1): 80-6.

Flanagan JC (1954) The critical incident technique. Psychological Bulletin 51(4): 327-59.

Flynn S (2010) Points race back as CAO offers show rise in early standards. The Irish Times, 23 August, 1.

Graham CR, Tripp TR, Seawright L, et al. (2007) Empowering or compelling reluctant participators using Audience Response Systems. Active Learning in Higher Education 8(3), 233-58.

Judson E and Sawada D (2002) Learning from the past and present: Electronic response systems in college lecture halls. Journal of Computers in Mathematics and Science Teaching 21(2): 167-81.

Kay RH and LeSage A (2009) Examining the benefits and challenges of using audience response system: A review of the literature. Computers \& Education 53(3): 819-27.

Keough SM (2012) Clickers in the classroom: A review and a replication. Journal of Management Education 36(6): 822-47.

Kuh GD (2001) Assessing what really matters to student learning: Inside the National Survey of Student Engagement. Change: The Magazine of Higher Learning 33(3): 10-7.

Latessa R and Mouw D (2005) Use of audience response system to augment interactive learning. Family Medicine 37(1): 12-4.

National Survey of Student Engagement (NSSE) (2002) From promise to progress: How colleges and universities are using student engagement results to improve collegiate quality. Annual Report, Indiana University, Bloomington, IN, December.

Nunnally J (1978) Psychometric Theory. New York: McGraw-Hill.

Preszler RW, Dawe A, Shuster CB, et al. (2007) Assessment of the effects of student response systems on student learning and attitudes over a broad range of biology courses. CBE-Life Sciences Education 6(1): $29-41$.

Roblyer MD and Wiencke WR (2003) Design and use of a rubric to assess and encourage interactive qualities in distance courses. American Journal of Distance Education 17(2): 77-98.

Rocca KA (2010) Student participation in the college classroom: An extended multidisciplinary literature review. Communication Education 59(2): 185-213.

Roschelle J, Penuel WR and Abrahamson L (2004) The networked classroom. Educational Leadership 61(5): $50-4$.

Salemi MK (2009) Clickenomics: Using a classroom response system to increase student engagement in a large-enrollment principles of economics course. Journal of Economic Education 40(4): 385-404.

Siau K, Sheng H and Nah F (2006) Use of a classroom response system to enhance classroom interactivity. IEEE Transactions on Education 49(3): 398-403.

Simpson V and Oliver M (2007) Electronic voting systems for lectures then and now: A comparison of research and practice. Australasian Journal of Educational Technology 23(2): 187-208.

Sims R (2003) Promises of interactivity: Aligning learner perceptions and expectations with strategies for flexible and online learning. Distance Education 24(1): 87-103.

Stuart SA, Brown MJ and Draper SW (2004) Using an electronic voting system in logic lectures: One practitioner's application. Journal of Computer Assisted Learning 20(2): 95-102. 
Usher A and Cervenan (2005) Global Higher Education Rankings 2005: Affordability and Accessibility in Comparative Perspectives. Toronto, ON, Canada: Educational Policy Institute.

Wentling TL, Park J and Peiper C (2007) Learning gains associated with annotation and communication software designed for large undergraduate classes. Journal of Computer Assisted Learning 23(1): 36-46.

Wolf-Wendel L, Ward K and Kinzie J (2009) A tangled web of terms: The overlap and unique contribution of involvement, engagement, and integration to understanding college student success. Journal of College Student Development 50(4): 407-28.

Zepke N and Leach L (2010) Improving student engagement: Ten proposals for action. Active Learning in Higher Education 11(3) 167-77.

\section{Author biographies}

Graham Heaslip lectures in operations and supply chain management. His research interests span humanitarian supply chains and logistics. His pedagogical research is concerned with learning technologies which encourage engagement. Address: Department of Management, School of Business, North Campus, NUI Maynooth, Maynooth, Co. Kildare, Ireland. [email: graham.heaslip@nuim.ie]

Paul Donovan is a Senior Lecturer in the field of human resource development. He is primarily interested in research which examines how training interventions are evaluated and learning is transferred in organisational settings. Address: Department of Management, School of Business, North Campus, NUI Maynooth, Maynooth, Co.Kildare, Ireland. [email: paul.donovan@nuim.ie]

John G Cullen's research is concerned with the concepts of vocation and calling in contemporary organisations and society, particularly in relation to the concept of sustainability. His pedagogical research is concerned with introduction reflexivity in large class scenarios. Address: Department of Management, School of Business, North Campus, NUI Maynooth, Maynooth, Co. Kildare, Ireland. [email: john.g.cullen@nuim.ie] 